Proceedings of the XXIII Conference on Applied Crystallography, Krynica Zdrój, Poland, September 20-24, 2015

\title{
Thin Layers XRD Study Technique on an Example of Cobalt Tetrafluoro Phthalocyanine
}

\author{
A.S. SukhikH ${ }^{a, b, *}$, T.V. BASOva ${ }^{a, b}$ AND S.A. GromiLOV ${ }^{a, b}$ \\ ${ }^{a}$ Nikolaev Institute of Inorganic Chemistry SB RAS, Lavrentiev Pr. 3, Novosibirsk 630090, Russia \\ ${ }^{b}$ Novosibirsk State University, Pirogova Str. 2, Novosibirsk, Russia
}

\begin{abstract}
Thin layers X-ray diffraction study technique utilizing single-crystal X-ray diffractometer equipped with microfocus X-ray tube is described. It is shown that the layers of the tetra-fluorinated cobalt phthalocyanine $\left(\mathrm{CoPcF}_{4}\right)$, deposited by thermal evaporation in vacuum on a polished surface of the substrate (glass, quartz), have a highly oriented polycrystalline structure. All the crystallites have the $(001)$ plane oriented along the surface of the substrate. $\mathrm{CoPcF}_{4} \mathrm{X}$-ray diffraction pattern indexing was conducted and unit cell parameters were determined. It is shown that crystal phase of both polycrystalline powder and thin layers of $\mathrm{CoPcF}_{4}$ are isostructural to that of $\alpha$-CoPc.
\end{abstract}

DOI: 10.12693 /APhysPolA.130.889

PACS/topics: 61.05.cp, 68.55.Nq

\section{Introduction}

Currently, metal phthalocyanines cause an increased scientific interest, because they are considered as promising materials for use in various electronic components such as thin-film diodes and organic field effect transistors [1-3], solar cells $[4,5]$ and gas sensors [6-8]. All these electronic devices contain metal phthalocyanines in form of a thin layers (a few tens of $\mathrm{nm}$ thick) deposited by thermal evaporation under vacuum or by molecular beam epitaxy on a pre-polished and prepared substrate. $\mathrm{X}$-ray diffraction (XRD) analysis of such thin samples is possible in grazing incidence X-ray diffraction geometry (GIXD) [9] using the synchrotron radiation source or a high-power X-ray tube with a rotating anode [10]. In Ref. [11] a study of $100 \mathrm{~nm}$ cobalt phthalocyanine layer by the means of powder diffractometer equipped with a special attachment $\left(0.4^{\circ}\right.$ long Soller slits) is described.

Cobalt phthalocyanine $(\mathrm{CoPc})$ and hexadecafluorinated cobalt phthalocyanine $\left(\mathrm{CoPcF}_{16}\right)$ are both sufficiently well described in the literature [12-14], while $\mathrm{CoPcF}_{4}$ is not mentioned at all. In the present paper we identify unit cell parameters and describe XRD technique for studying thin layers of $\mathrm{CoPcF}_{4}$ on serial single-crystal diffractometer with a microfocus tube and 2D CCD-detector.

\section{Experimental setup}

$\mathrm{CoPcF}_{4}$ was synthesized by heating a $4: 1$ mixture of 4fluorophthalonitrile (Aldrich) and anhydrous cobalt(II) chloride in a glass tube at $220^{\circ} \mathrm{C}$ during $6 \mathrm{~h}$. After cooling to room temperature the mixture was washed with ethanol and acetone to remove organic impurities. The precipitate was purified by gradient sublimation in vacuum $\left(10^{-5}\right.$ Torr $)$ at $450^{\circ} \mathrm{C}$. $\mathrm{CoPcF}_{4}$ was prepared

\footnotetext{
* corresponding author; e-mail: a_sukhikh@niic.nsc.ru
}

as a statistical mixture of four regioisomers due to the various possible positions of fluorine substituents. No attempt was made to separate the $\mathrm{CoPcF}_{4}$ isomers.

Thin $\mathrm{CoPcF}_{4}$ layers were obtained by organic molecular beam deposition (OMBD) technique (VUP-5M vacuum station, $10^{-5}$ Torr, Knudsen cell source at $460^{\circ} \mathrm{C}$ ). $10 \times 10 \mathrm{~mm}^{3}$ glass plates $(0.1 \mathrm{~mm}$ thick $)$ and polished ends of fused quartz rods ( $1 \mathrm{~mm}$ in diameter) were used as substrates. During the thin layer growth the substrates were held at room temperature, at a distance of $50 \mathrm{~mm}$ from the source with the surfaces perpendicular to the source. Deposition time was in range of 30-60 min. The samples obtained were solid transparent blue layers with estimated thickness of $60-80 \mathrm{~nm}$.

XRD measurements were carried out using conventional Bragg-Brentano geometry (Shimadzu XRD-7000 powder X-ray diffractometer, $\mathrm{Cu} K_{\alpha}$, Bragg-Brentano geometry with $\theta-\theta$ goniometer, scintillation counter) and 2D GIXD geometry [15-18] using Bruker DUO singlecrystal diffractometer $(\lambda=1.5418 \AA, 0.6 \mathrm{~mm}$ output collimator, $1024 \times 1024 \mathrm{CCD}$ detector, $60 \times 60 \mu \mathrm{m}^{2}$ physical pixel size), equipped with an Incoatec $\mathrm{I} \mu \mathrm{Cu}$ microfocus X-ray tube $\left(\mathrm{Cu} K_{\alpha}, 45 \mathrm{kV}, 0.64 \mathrm{~mA}\right)$.

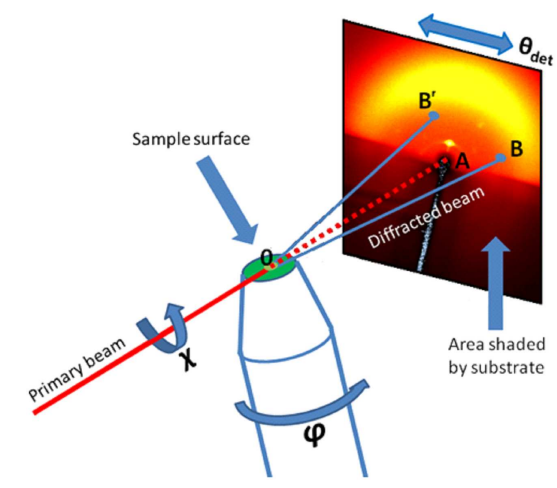

Fig. 1. Experimental setup for studying thin layers in GIXD geometry on the Bruker DUO single-crystal diffractometer. 
The general scheme of the measurements is shown in Fig. 1. 4-circle goniometer allows for: turning the sample around its own axis $(\varphi)$ and around primary beam $(\chi)$, changing primary beam incidence angle $\left(\theta_{\text {sample }}\right)$, changing detector position $\left(\theta_{\text {det }}\right)$ and the distance from the center of the sample to the detector ( $L, O A$ segment on picture). The sample on the polished end of the fused quartz rod was directly mounted into the goniometer head. Alignment was performed using a standard video camera. The angle between the primary beam and detector $\left(\theta_{\text {det }}\right)$ was $10^{\circ}$. The distance from the center of the sample to the detector $(L)$ was varied in range of $40 \div 160 \mathrm{~mm}$, and $\theta_{\text {sample }}$ angle - in range of $0 \div 3^{\circ}$ $\left(0.5^{\circ}\right.$ step $)$. Measurements carried out at constant values of the angle $\varphi$, in the range $0 \div 180^{\circ}\left(30^{\circ}\right.$ step), showed that the general view of the observed diffraction patterns remains constant.

\section{Results and discussion}

Figure 2 shows XRD patterns for $\mathrm{CoPcF}_{4}$ in comparison with the theoretical diffraction data for $\alpha$-CoPc and $\beta$-CoPc. The last ones were calculated according to the known structural data: $a=12.090(8), b=3.754(2), c=$ 12.800(9) $\AA, \alpha=88.96(6), \beta=90.97(6), \gamma=95.09^{\circ}(7)$, $V=578.48 \AA^{3}, P \overline{1}$ for $\alpha-\operatorname{CoPc}[19]$ and $a=14.495(5)$, $b=4.742(4), c=19.107(5) \AA, \alpha=90, \beta=120.76(2)$, $\gamma=90^{\circ}, V=1128.56 \AA^{3}, P 21 / c$ for $\beta$-CoPc [20]. Powder Cell 2.5 [21] software was used for calculations. Comparison of diffraction patterns for $\alpha-\mathrm{CoPc}$ and $\mathrm{CoPcF}_{4}$ (Fig. 2a,c) has allowed us to conclude that these phases are isostructural. Positions of the 19 most intensive

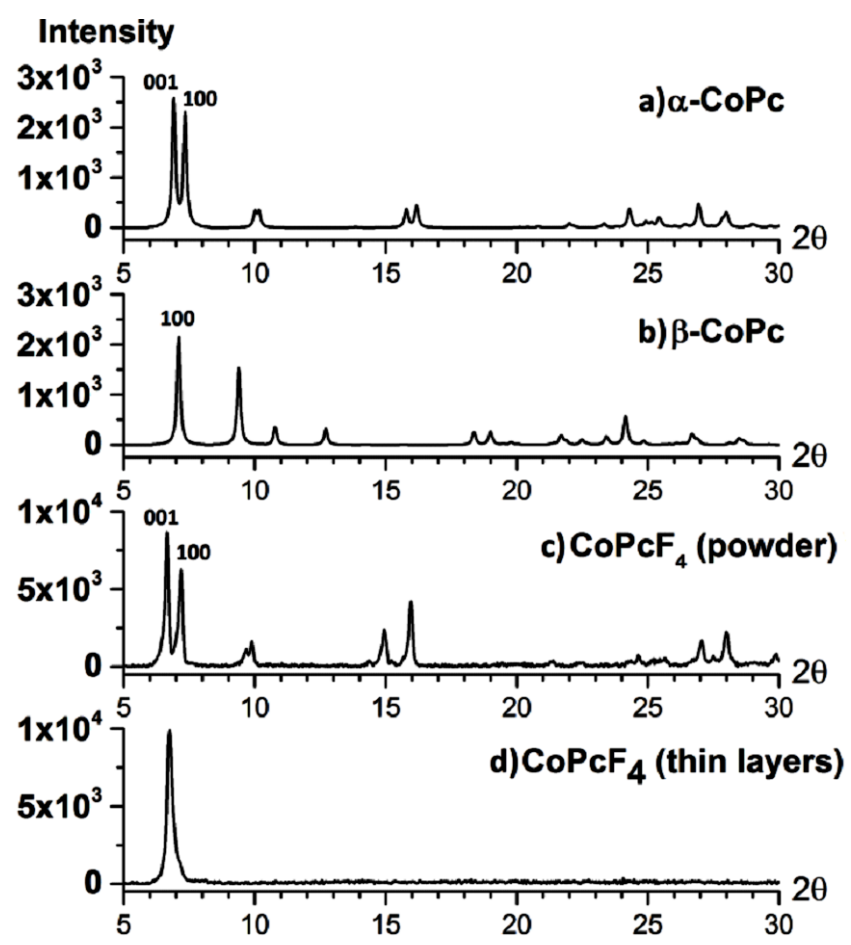

Fig. 2. Comparison of theoretical $\mathrm{CoPc}$ diffraction patterns and experimental $\mathrm{CoPcF}_{4}$ diffraction patterns (Shimadzu XRD-7000, $\mathrm{Cu} K_{\alpha}$ ).
$\mathrm{CoPcF}_{4}$ single diffraction peaks were determined using Origin9.1. By analogy with the corresponding $\alpha$-CoPc diffraction peaks, $h k l$ indexes were assigned to the 11 of $19 \mathrm{CoPcF}_{4}$ diffraction peaks and then preliminary unit cell parameters were calculated by the least squares method. Based on the preliminary results, indexing and refinement of all 19 diffraction peaks were carried out, yielding the final parameters: $a=12.41(5), b=3.67(1)$, $c=13.35(6) \AA, \alpha=88.4(1), \beta=89.00(8), \gamma=96.0(1)^{\circ}$, $V=605(1) \AA^{3}, P \overline{1}$.

The XRD pattern of $\mathrm{CoPcF}_{4}$ thin layers deposited on glass plates is shown in Fig. 2d. Only the single diffraction reflex is present, indicating that the crystallites are ideally oriented relative to the substrate plane. However because of that, it is impossible to assert unequivocally that the resulting layer of $\mathrm{CoPcF}_{4}$ has the same crystalline phase as polycrystalline $\mathrm{CoPcF}_{4}$. It is known $[22,23]$ that $\mathrm{CoPc}$ can be deposited on the substrate in two possible crystal phases - metastable $\alpha$ phase (Fig. 2a) and stable $\beta$-phase (Fig. 2b), and by heating the metastable $\alpha$-phase gradually turns into the $\beta$-phase. Thus, in our case a thin layer of $\mathrm{CoPcF}_{4}$, obtained by heating polycrystalline powder to $460{ }^{\circ} \mathrm{C}$ may contain two crystalline phases in varying proportion. Attempts to find additional diffraction peaks for unambiguous identification by increasing the sampling time were not successful, so further research was carried out in the 2D GIXD geometry.

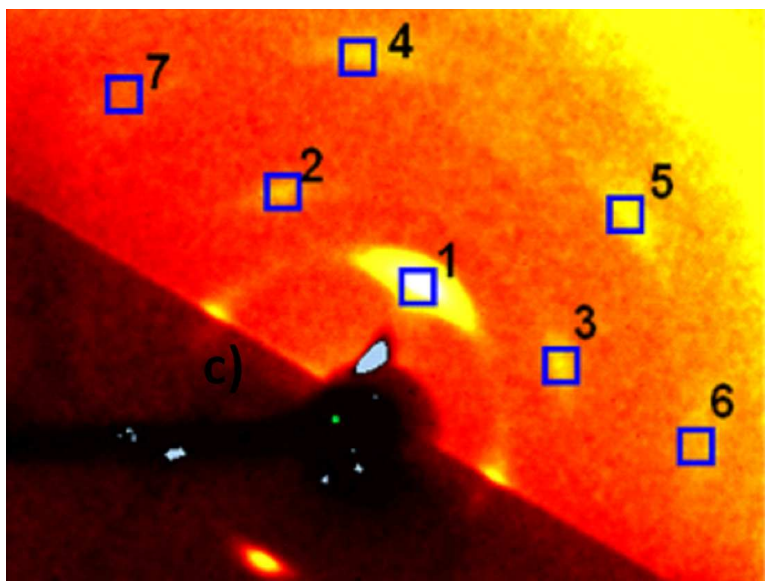

Fig. 3. The diffraction pattern of the $\mathrm{CoPcF}_{4}$ sample obtained by $2 \mathrm{D}$ GIXD $\left(\chi=60^{\circ}, L=40 \mathrm{~mm}\right.$, $\theta_{\text {det }}=10^{\circ}$ ).

In all cases, local diffraction spots typical of singlecrystal sample were observed (see Fig. 3). By turning the sample relative to the primary beam at a fixed angle $\chi$ corresponding rotation of the diffraction pattern was observed. (001) reflex is the most intensive; the other pairs of reflexes have a relative intensity of $2 \%$ and about 1.5 times higher than the background level. Each crystal plane corresponds to a pair of symmetrically arranged reflexes: $2,3-(101),(-101) ; 4,5-(102) ; 6,7-$ $(-201)$. Positions of the diffraction peaks centers and angles between the corresponding planes and the sub- 
strate surface were determined using Origin9.1 (Gauss2D function). After switching to the interplanar distances the following results were obtained: $(001)-13.11 \AA$, $0^{\circ} ;(101),(-101)-9.18 \AA, 44.5^{\circ} ;(102)-5.87 \AA, 27^{\circ}$; $(-201)-5.58 \AA, 63.5^{\circ}$, which are fully consistent with unit cell parameters given earlier.

\section{Conclusions}

It is shown that $\mathrm{CoPcF}_{4}$ layers deposited by OMBD on a polished surface of the substrate (glass, quartz) have highly oriented polycrystalline structure. When studying these layers in the Bragg-Brentano geometry, only the orders of reflections from one crystallographic plane are available, as demonstrated in Fig. 2d. This makes it difficult to radiographically identify the crystal phase. Using the 2D GIXD, we have shown that thin layer samples of $\mathrm{CoPcF}_{4}$ are isostructural to $\alpha-\mathrm{CoPc}$. In addition, 2D GIXD allows us to estimate the angles between the substrate surface and crystal planes for which the corresponding reflexes can be clearly observed on diffraction pattern. Because all of the crystallites have (001) plane parallel to the substrate plane, then the angle between the (001) plane and any other plane is equal to the angle between this plane and the substrate surface. Such information may be useful for diffraction pattern indexing when the unit cell parameters are unknown.

\section{Acknowledgments}

This work was supported by the Russian Scientific Foundation (project N 15-13-10014).

\section{References}

[1] J. Zhang, J. Wang, H. Wang, Y. Donghang, Appl. Phys. Lett. 84, 142 (2004).

[2] F. Wahab, M.H. Sayyad, M. Tahir, D.N. Khan, F. Aziz, M. Shahid, M.A. Munawar, J.A. Chaudry, G. Khan, Synth. Met. 198, 175 (2014).

[3] F. Wahab, M.H. Sayyad, D.N. Khan, M. Tahir, F. Aziz, M. Shahid, M.A. Munawar, J.A. Chaudry, Mater. Sci. Semicond. Process. 26, 101 (2014).

[4] H.S. Soliman, A.A.M. Farag, N.M. Khosifan, M.M. El-Nahass, Thin Solid Films 516, 8678 (2008).
[5] C.Y. Kwong, A.B. Djurišicê, P.C. Chui, L.S.M. Lam, W.K. Chan, Appl. Phys. A 77, 555 (2003).

[6] T. Sizun, M. Bouvet, Y. Chen, J.M. Suisse, G. Barochi, J. Rossignol, Sens. Actuat. B 159, 163 (2011).

[7] A. Kumar, N. Joshi, S. Samanta, A. Singh, A.K. Debnath, A.K. Chauhan, M. Roy, R. Prasad, K. Roy, M.M. Chehimi, D.K. Aswal, S.K. Gupta, Sens. Actuat. B 206, 653 (2015).

[8] A. Singh, S. Samanta, A. Kumar, A.K. Debnath, R. Prasad, P. Veerender, V. Balouria, D.K. Aswal, S.K. Gupta, Org. Electron. 13, 2600 (2012).

[9] P. Dutta, Curr. Sci. 78, 1478 (2000).

[10] R.D. Tarey, R.S. Rastogi, K.L. Chopra, The Rigaku J. 4, 11 (1987).

[11] A. Singh, S. Samanta, A. Kumar, A.K. Debnath, D.K. Aswal, S.K. Gupta, J.V. Yakhmi, Y. Hayakawa, S.K. Deshpande, Org. Electron. 11, 1835 (2010).

[12] J. Guo, H. Li, H. He, D. Chu, R. Chen, J. Phys. Chem. C 115, 8494 (2011).

[13] F. Petraki, H. Peisert, J. Uihlein, U. Aygül, T. Chassé, Beilstein J. Nanotechnol. 5, 524 (2014).

[14] J. Ouyang, K. Shigehara, A. Yamada, F.C. Anson, J. Electroanal. Chem. Interf. Electrochem. 297, 489 (1991).

[15] A.S. Sukhikh, T.V. Basova, S.A. Gromilov, J. Struct. Chem., 2016, in press.

[16] H.Y. Chen, J. Hou, A.E. Hayden, H. Yang, K.N. Houk, Y. Yang, Adv. Mater. 22, 371 (2010).

[17] W.H. Lee, J. Park, S.H. Sim, S.B. Jo, K.S. Kim, B.H. Hong, K. Cho, Adv. Mater. 23, 1752 (2011).

[18] H. Yang, T.J. Shin, M.M. Ling, K. Cho, C.Y. Ryu, Z. Bao, J. Am. Chem. Soc. 127, 11542 (2005).

[19] P. Ballirano, R. Caminiti, C. Ercolani, A. Maras, M.A. Orru, J. Am. Chem. Soc. 120, 12798 (1998).

[20] G.A. Williams, B.N. Figgis, R. Mason, S.A. Mason, P.E. Fielding, J. Chem. Soc. Dalton Trans. 9, 1688 (1980).

[21] W. Kraus, G. Nozle, J. Appl. Crystallogr. 29, 301 (1996).

[22] S.I. Shihub, R.D. Gould, Phys. Status Solidi A 139, 129 (1993).

[23] M.M. El-Nahhas, Z. El-Gohary, H.S. Soliman, Opt. Laser Technol. 35, 523 (2003). 